\title{
Sleep quality predicts quality of life in chronic obstructive pulmonary disease
}

This article was published in the following Dove Press journal:

International Journal of Chronic Obstructive Pulmonary Disease

21 December 2010

Number of times this article has been viewed

\author{
Steven M Scharf ${ }^{*}$ \\ Nimrod Maimon ${ }^{2 *}$ \\ Tzahit Simon-Tuval ${ }^{3}$ \\ Barbara J Bernhard-Scharf ${ }^{4}$ \\ Haim Reuveni ${ }^{2}$ \\ Ariel Tarasiuk ${ }^{2}$ \\ 'Department of Pulmonary \\ and Critical Care, University \\ of Maryland, Baltimore, MD, USA; \\ ${ }^{2}$ Faculty of Health Sciences, \\ Ben-Gurion University, Beersheba, \\ Israel; ${ }^{3}$ Guilford Glazer School \\ of Business and Management, \\ Ben Gurion University, Beersheba, \\ Israel; ${ }^{4} \mathrm{Mt}$. Washington Pediatric \\ Hospital, Baltimore, MD, USA; The \\ study was performed at the Soroka \\ University Medical Center, Beer \\ Sheva, Israel \\ *Drs Scharf and Maimon contributed \\ equally to this manuscript.
}

Purpose: Chronic obstructive pulmonary disease (COPD) patients may suffer from poor sleep and health-related quality of life. We hypothesized that disturbed sleep in COPD is correlated with quality of life.

Methods: In 180 patients with COPD (forced expired volume in 1 second [FEV $]$ 47.6 $\pm 15.2 \%$ predicted, $77.8 \%$ male, aged $65.9 \pm 11.7$ years), we administered general (Health Utilities Index 3) and disease-specific (St George's Respiratory) questionnaires and an index of disturbed sleep (Pittsburgh Sleep Quality Index).

Results: Overall scores indicated poor general (Health Utilities Index 3: $0.52 \pm 0.38$ ), disease-specific (St George's: $57.0 \pm 21.3$ ) quality of life and poor sleep quality (Pittsburgh $11.0 \pm 5.4)$. Sleep time correlated with the number of respiratory and anxiety symptoms reported at night. Seventy-seven percent of the patients had Pittsburg scores $>5$, and the median Pittsburgh score was 12 . On multivariate regression, the Pittsburgh Sleep Quality Index was an independent predictor of both the Health Utilities Index 3 and the St George's scores, accounting for 3\% and $5 \%$, respectively, of the scores. Only approximately $25 \%$ of the patients demonstrated excessive sleepiness (Epworth Sleepiness Scale $>9$ ).

Conclusions: Most patients with COPD suffer disturbed sleep. Sleep quality was correlated with general and disease-specific quality of life. Only a minority of COPD patients complain of being sleepy.

Keywords: COPD, quality of life, Pittsburgh Sleep Quality Index, St George's Respiratory Questionnaire, Health Utilities Index, sleep quality

\section{Introduction}

In chronic obstructive pulmonary disease (COPD), symptom burden is more closely related to health-related quality of life (HrQOL) than to forced expired volume in one second $\left(\mathrm{FEV}_{1}\right) \cdot{ }^{1-3}$ It is now accepted that HrQOL is an important endpoint for clinical trials in COPD. ${ }^{4,5}$

Poor sleep quality influences HrQOL in COPD. ${ }^{6}$ Physiologic changes in COPD lead to fragmented sleep, including nocturnal airflow obstruction, arterial oxygen desaturation, hypercapnia, and use of accessory muscles of respiration. ${ }^{6,7}$ Patients with COPD frequently complain of difficulty initiating and maintaining sleep and increased number of arousals during sleep. ${ }^{8-10}$ Indeed, data from two recent small studies indicate that poor sleep quality is a correlate of HrQOL in COPD. ${ }^{11,12}$ To date, however, there are few studies detailing the relationship between sleep quality and HrQOL in COPD. Also, there are few studies accounting for effects of socioeconomic factors, comorbidity burden, and medication use on COPD and sleep-related HrQOL. 
We performed a cross-sectional study of HrQOL on a convenience sample of stable COPD patients coming to the pulmonary clinic for routine follow-up visits, incorporating different metrics of HrQOL: demographic, physiologic, and socioeconomic information; medication use; and comorbidity burden. We wished to characterize the extent of sleep disturbances in patients with COPD. Further, we wished to determine predictors of HrQOL from among commonly measured variables and the contribution of sleep disturbance to HrQOL. We hypothesized that sleep disturbances would be independent predictors of HrQOL in COPD.

\section{Methods}

The study was performed at the Pulmonary Clinic of the Soroka University Medical Center, Beer Sheva, Israel, following approval by the Ethics Committee.

This exploratory study included a four-week recall questionnaire, spirometry, and abstraction of additional patient specific data from the patients' major health maintenance organization data files. In this study, inclusion criteria were: 1 ) age $>35$ years; 2 ) smoking $\geq 10$ pack-years; 3) pulmonologist-diagnosed COPD based on history of smoking, airflow obstruction on spirometry, and the presence of at least one symptom of COPD (ie, exercise-limiting dyspnea, chronic cough, sputum production); 4) no exacerbations within one month; and 5) no hospitalization/ urgent care visits within one month. Exclusion criteria were: 1) other major pulmonary diagnoses; or 2) disease expected to shorten life span to $<3$ years. Spirometry was performed on the day of questionnaire administration and included forced vital capacity (FVC) and $\mathrm{FEV}_{1}$. Severity was staged according to the Global Initiative for Obstructive Lung Disease (GOLD). ${ }^{14}$

The four-week recall questionnaire included validated scales, additional symptom questions, and demographic and socioeconomic information. Hebrew translations of specific scales were validated. ${ }^{15}$ These included: 1) Health Utilities Index 3 (HUI3), ${ }^{16-18}$ a generic index rating health from 0 (very ill) to 1 (perfect health) where scores of less than 0 are allowed (quality of life rated as worse than death); 2) St George's Respiratory Questionnaire (SGRQ), ${ }^{19,20}$ a scale of COPD-specific quality of life ranging from $0 \%$ (best) to $100 \%$ (worst); 3) Pittsburgh Sleep Quality Index (PSQI), ${ }^{21}$ an index of self-rated quality of sleep, with scores from 0 to 21 , with increasing score meaning worse sleep quality and a score of $>5$ indicating poor sleep; and 4) Epworth Sleepiness Scale (ESS) ${ }^{22}$ rating sleepiness from 0 (none) to 24 (worst), with scores $>9$ indicating excessive sleepiness. In addition to these, we asked questions on the frequency of specific nocturnal respiratory and anxiety symptoms using a survey entitled Sleep Symptom Questionnaire (Figure 1). There is no composite score. Demographics included age, gender, body mass index (BMI), smoking status (current, ex-smoker), and pack-years smoking. Socioeconomic status included: 1) income relative to the Israeli average; 2) years of schooling; 3) employment status; and 4) marital status. Questionnaires were administered by trained interviewers.

One hundred seventy-seven of the patients were members of the Clalit Health Services, the largest health maintenance organization in Israel. For these patients, we reviewed the Clalit database to obtain information on medication use within the quarter prior to the administration of the questionnaire and

\begin{tabular}{|l|c|c|c|c|c|}
\hline & $\begin{array}{c}\text { Not during } \\
\text { the past } \\
\text { month }\end{array}$ & $\begin{array}{c}\text { Less than } \\
\text { once a week }\end{array}$ & $\begin{array}{c}\text { Once or } \\
\text { twice a } \\
\text { week }\end{array}$ & $\begin{array}{c}\text { Three or } \\
\text { more times } \\
\text { a week }\end{array}$ & $\begin{array}{c}\text { Don't } \\
\text { know }\end{array}$ \\
\hline Whistle or wheeze from chest & 0 & 1 & 2 & 3 & 4 \\
\hline Cough & 0 & 1 & 2 & 3 & 4 \\
\hline Shortness of breath & 0 & 1 & 2 & 3 & 4 \\
\hline Chest pain while in bed & 0 & 1 & 2 & 3 & 4 \\
\hline $\begin{array}{l}\text { Lying awake during your } \\
\text { sleep time feeling worried, } \\
\text { depressed, or sad }\end{array}$ & 0 & 1 & 2 & 3 & 4 \\
\hline $\begin{array}{l}\text { Lying awake during your } \\
\text { sleep time with thoughts } \\
\text { racing through your mind }\end{array}$ & 0 & 1 & 2 & 3 & 4 \\
\hline Heartburn during sleep time & 0 & 1 & & & \\
\hline Palpitations during sleep time & 0 & 1 & 2 & 3 & 4 \\
\hline
\end{tabular}

Figure I Sleep Symptom Questionnaire.

Note: On average, how many days/nights during the last month have you had the following WHILE ASLEEP OR TYRING TO SLEEP? (circle your best estimate). 
the presence of concomitant obstructive sleep apnea (OSA). Data on concomitant comorbidities were gathered to allow calculation of the age-adjusted Charlson Comorbidity Score with Deyo modification (CCI). ${ }^{24-27}$

\section{Data analysis}

Data were expressed as mean (standard deviation [SD]) and median $(25 \%-75 \%)$. Bivariate associations were assessed using Pearson product-moment coefficients and least-squares regression. Backwards stepwise multivariate regression was used to determine independent effects of significant bivariate predictors. Differences between means were tested using unpaired $t$-tests. Rates and proportions were tested using Chisquare analysis. The null hypothesis was rejected at the 5\% level. Differences in indices of HrQOL with different levels of COPD severity (according to GOLD) were tested using one-factor analysis of variance (ANOVA). Data analysis was performed using Statistical Package for the Social Sciences, version 17 (SPSS Inc, Chicago, IL, USA) or GBstat v9 (Dynamic Microsystems Inc, Silver Spring, MD, USA).

\section{Results}

Two hundred stable COPD patients were approached sequentially when they came in for routine clinic appointments. Twenty of these refused participation or had insufficient knowledge of the Hebrew language to take the questionnaires. Table 1 shows spirometric, demographic, and socioeconomic data. Data were not available for arterial blood gases when stable in this cohort. Data were available for 164 of the patients on room air oxygen saturation, taken the same time as the spirometry. This information is also presented in Table 1. Most patients were older than 60 years, ranked their income as less than the Israeli average, were on a pension, were male, were past smokers, and had COPD deemed "severe" or "very severe" according to GOLD classification. HrQOL ratings, whether general or specific, were poor (Table 2). The mean PSQI was high, indicating self-rated poor sleep quality. The majority of patients rated sleep as abnormal (PSQI $>5$ ). On the other hand, only a minority of respondents rated daytime sleepiness as abnormal (ESS > 9). Twenty-seven of our patients carried the diagnosis of OSA. We had no data on severity of OSA, nor did we have continuous positive airway pressure (CPAP) treatment or compliance rates. However, as there were no differences in any reported metric or HrQOL score between patients with and without OSA (data not shown), we have retained the patients with known OSA in the analysis.

\section{Sleep quality}

Table 3 lists some specific sleep symptoms from answers on the PSQI. The median self-reported sleep time was only five hours

Table I Demographics and spirometric data $(N=180)$

\begin{tabular}{|c|c|c|c|}
\hline Variable & Mean (SD) or proportion (\%) & Median (25\%-75\%) & \\
\hline Age (yrs) & $65.9(11.7)$ & $66.7(59.5-73.2)$ & \\
\hline $\mathrm{BMI}\left(\mathrm{kg} / \mathrm{m}^{2}\right)$ & $27.3(5.5)$ & $26.6(23.5-30.1)$ & \\
\hline Pack-yrs smoking & $49.1(29.5)$ & $40.0(27.0-60.0)$ & \\
\hline Years of education & $9.24(5.43)$ & $10(6-12)$ & \\
\hline FVC (L) & $2.17(0.7)$ & $2.16(1.64-2.6 I)$ & \\
\hline FVC (\% pred) & $64.7(16.3)$ & $66.0(52-75)$ & \\
\hline $\mathrm{FEV}_{1}(\mathrm{~L})$ & $1.24(0.50)$ & $1.18(0.88-1.53)$ & \\
\hline $\mathrm{FEV}_{\text {, }}$ (\% pred) & $47.6(15.2)$ & $46(36-58)$ & \\
\hline FEV,/FVC (\%) & $57.5(12.3)$ & $58.7(50.2-65.3)$ & \\
\hline Baseline $\mathrm{O}_{2}$ saturation (\%) & $95.0(2.9)$ & $96.0(94 \%-97 \%)$ & \\
\hline $\mathrm{CCl}$ & $6.63(3.52)$ & $6(4-9)$ & \\
\hline Number of medications (all) & $4.6(2.2)$ & $5(3-6)$ & \\
\hline Number of pulmonary & $2.0(1.1)$ & $2(1-3)$ & \\
\hline \multicolumn{4}{|l|}{ medications (not including } \\
\hline \multicolumn{4}{|l|}{ systemic steroids) } \\
\hline Males & 140 (77.8\%) & & \\
\hline Current smokers & $43(28.9 \%)$ & & \\
\hline Earn less than average & $135(80.3 \%)$ & & \\
\hline \multicolumn{4}{|l|}{ income (8000 NIS/month) } \\
\hline On pension & $126(72.4 \%)$ & & \\
\hline Currently married & $136(76.4 \%)$ & & \\
\hline \multirow[t]{2}{*}{ GOLD class } & Moderate (2) & Severe (3) & Very severe (4) \\
\hline & $19(10.6 \%)$ & $83(46.1 \%)$ & $23(12.8 \%)$ \\
\hline
\end{tabular}

Abbreviations: BMI, body mass index $\left(\mathrm{kg} / \mathrm{m}^{2}\right)$; $\mathrm{CCl}$, Charlson Comorbidity Index; GOLD, global initiative for chronic obstructive lung disease; FVC, forced vital capacity; FVC\%, FVC\% predicted; FEV , forced expired volume in one second; FEV \%, FEV, as percent predicted. 
Table 2 Quality of life scores

\begin{tabular}{|c|c|c|c|c|}
\hline HrQOL instrument & Mean (SD) & Median (25\%-75\%) & & \\
\hline SGRQ & $57.0(21.3)$ & $59.6(4 I .7-75.6)$ & & \\
\hline HUI3 & $0.52(0.38)$ & $0.62(0.27-0.84)$ & & \\
\hline PSQI & $11.0(5.4)$ & $12.0(6-16)$ & & \\
\hline ESS & $7.0(4.8)$ & $6.0(3-9)$ & & \\
\hline SGRQ Symptom domain & $54.7(25.4)$ & $55.9(33.3-75.7)$ & & \\
\hline SGRQ Activity domain & $67.4(24.7)$ & $72.6(53.2-87.2)$ & & \\
\hline SGRQ Impact domain & $51.9(22.9)$ & $54.8(34.2-69.4)$ & & \\
\hline Pittsburgh $>5$ & I 38 (77.7\%) & & & \\
\hline ESS $>9$ & $44(24.7 \%)$ & & & \\
\hline HrQOL and sleep quality according & Mild (I) & Moderate (2) & Severe (3) & Very severe (4) \\
\hline \multicolumn{5}{|l|}{ to GOLD class - mean (SD) } \\
\hline HUI3 & $0.40(0.33)$ & $0.58(0.36)$ & $0.53(0.35)$ & $0.39(0.5 \mathrm{I})$ \\
\hline SGRQ & $47.2(16.5)$ & $53.5(24.5)$ & $57.9(20.3)$ & $65.3(20.8)$ \\
\hline PSQI & $12.7(3.2)$ & I I.6 (4.8) & $10.6(5.6)$ & $10.9(5.6)$ \\
\hline
\end{tabular}

Note: The differences in HUI3, SGRQ and PSQI among GOLD classes were all NS (ANOVA).

Abbreviations: HrQOL, health-related quality of life; SGRQ, St Georges Respiratory Questionnaire; HUI3, Health Utilities Index 3; PSQI, Pittsburgh Sleep Quality Index; ESS, Epworth Sleepiness Scale.

and the median latency to sleep was 30 minutes. The patients reported a median time in bed of approximately eight hours.

Self-reported respiratory symptoms were fairly common ranging from $48 \%$ to $74 \%$ of the patients. Looking at sleep

Table 3 Specific answers on the PSQI

\begin{tabular}{ll}
\hline Specific symptom/item & Median (25\%-75\%) \\
\hline Bedtime (clock time) & $22: 00(22: 45-02: 00)$ \\
Rise time (clock time) & $06: 00(5: 00-6: 45)$ \\
Latency to sleep (min) & $30.00(2-45)$ \\
Estimated sleep time (hours) & $5(4-6.5)$ \\
Symptoms or items & Number (\%) reporting \\
$\geq 3$ times per week & $\geq 3$ times/week \\
Latency to sleep $<30$ minutes & $92(51.7 \%)$ \\
Waken at night & $133(74.7 \%)$ \\
Go to BR at night & $134(74.9 \%)$ \\
Can't breathe at night & $63(35.2 \%)$ \\
Cough or snore loudly & $85(48.0 \%)$ \\
Think it is too cold & $29(16.2 \%)$ \\
Think it is too hot & $66(36.9 \%)$ \\
Bad dreams & $19(10.7 \%)$ \\
Feel pain at night & $46(25.7 \%)$ \\
Other problems & $40(22.2 \%)$ \\
Took sleep meds to help sleep & $20(11.1 \%)$ \\
Difficulty staying awake during & $12(6.7 \%)$ \\
activities in the day & \\
Snores loudly & $55(31.8 \%)$ \\
Witnessed apneas & $38(21.5 \%)$ \\
Excessive movements of the legs & $44(24.6 \%)$ \\
Nocturnal confusion & $5(2.8 \%)$ \\
Restless sleep & $56(31.3 \%)$ \\
Other discomfort & $45(32.6 \%)$ \\
Snore/cough or witnessed apneas & $74(41 \%)$ \\
Snore/cough or WA + sleepy & $5(2.8 \%)$ \\
(“classic OSA”) & \\
\hline
\end{tabular}

Abbreviations: BR, bathroom; OSA, obstructive sleep apnea; PSQI, Pittsburgh Sleep Quality Index; WA, witnessed apneas. apnea symptoms, snoring, witnessed apneas (by bed partner), and sleepiness, $31.8 \%$ reported frequent ( $\geq 3$ times per week) snoring, $21.5 \%$ witnessed apneas at night, but only $6.7 \%$ reported sleepiness interfering with daily activities. As a surrogate for possible sleep apnea, ${ }^{23}$ we found that $41 \%$ reported severe snoring and/or witnessed apneas.

\section{Nocturnal symptoms and sleep quality}

Nocturnal wheezing, worrying, and uncontrolled thoughts were associated with low sleep times (Table 4). Other specific respiratory symptoms, although common, were not significantly associated with sleep times, including cough, dyspnea, chest pain, heartburn, and palpitations. We found a significant association between the number of nocturnal symptoms and sleep time: sleep time $=6.025-0.317 \times$ number of nocturnal symptoms; $R=-0.38, P<0.0001$.

\section{Predictors of sleep quality and HrQOL}

Bivariate predictors of HrQOL are shown in Table 5. On backwards stepwise multivariate analysis (Table 6), the independent significant predictors of SGRQ were education, HUI3, PSQI, and $\mathrm{FEV}_{1} \%$ ( $48 \%$ of the variance). For PSQI, the significant independent predictors were HUI3 and SGRQ ( $30 \%$ of the variance). For HUI3, the independent significant predictors were age, SGRQ, and PSQI ( $49 \%$ of the variance). The unique contribution of each independent variable on the variance of the dependent variable was expressed as the square of the semipartial correlation coefficient (Table 6). For the SGRQ, the PSQI uniquely contributes $5 \%$, and for the HUI3, PSQI contributes $3 \%$ of the variance for the dependent variables. 
Table 4 Specific night-time sleep symptoms (Sleep Symptom Questionnaire) and self-reported sleep time

\begin{tabular}{|c|c|c|c|c|c|}
\hline Symptom & Frequency & $<5$ hours sleep & $\geq 5$ hours sleep & Missing $^{\mathrm{a}}$ & $P$ \\
\hline \multirow[t]{2}{*}{ Nocturnal wheezing } & $<3 \times$ per week & $42(40 \%)$ & $61(59 \%)$ & I (I\%) & 0.0254 \\
\hline & $\geq 3 \times$ per week & $46(62 \%)$ & $23(31 \%)$ & $5(7 \%)$ & \\
\hline \multirow[t]{2}{*}{ Nocturnal cough } & $<3 \times$ per week & $37(40 \%)$ & $53(47 \%)$ & $3(3 \%)$ & NS \\
\hline & $\geq 3 \times$ per week & 51 (59\%) & $32(37 \%)$ & $3(3 \%)$ & \\
\hline \multirow[t]{2}{*}{ Nocturnal dyspnea } & $<3 \times$ per week & 40 (47\%) & $46(53 \%)$ & $0(0 \%)$ & NS \\
\hline & $\geq 3 \times$ per week & 48 (53\%) & 37 (4l\%) & $6(7 \%)$ & \\
\hline \multirow[t]{2}{*}{ Nocturnal chest pain } & $<3 \times$ per week & $56(45 \%)$ & $65(52 \%)$ & $4(3 \%)$ & NS \\
\hline & $\geq 3 \times$ per week & $31(60 \%)$ & $19(37 \%)$ & $2(4 \%)$ & \\
\hline Nocturnal worry, & $<3 \times$ per week & 48 (4I\%) & $68(58 \%)$ & $2(2 \%)$ & 0.0135 \\
\hline depression, nervousness & $\geq 3 \times$ per week & $40(66 \%)$ & $17(28 \%)$ & $4(7 \%)$ & \\
\hline Nocturnal lying awake & $<3 \times$ per week & $38(38 \%)$ & $59(60 \%)$ & $2(2 \%)$ & 0.0167 \\
\hline with thoughts running & $\geq 3 \times$ per week & $50(63 \%)$ & $26(33 \%)$ & $4(5 \%)$ & \\
\hline \multicolumn{6}{|l|}{ through head } \\
\hline \multirow[t]{2}{*}{ Nocturnal heartburn } & $<3 \times$ per week & 65 (45\%) & $76(52 \%)$ & $4(3 \%)$ & NS \\
\hline & $\geq 3 \times$ per week & $23(68 \%)$ & $9(26 \%)$ & $2(6 \%)$ & \\
\hline \multirow[t]{2}{*}{ Nocturnal palpitations } & $<3 \times$ per week & 71 (47\%) & 77 (5।\%) & $4(3 \%)$ & NS \\
\hline & $\geq 3 \times$ per week & 17 (63\%) & $8(30 \%)$ & $2(7 \%)$ & \\
\hline
\end{tabular}

Notes: Expressed as number (percent of row). aMissing = no response, or responded “I don't know".

We expressed the slope of the bivariate regression lines as the change in SGRQ in standard deviations for the whole group, against the change in the HrQOL index in standard deviations for the whole group. This standardized change is an indicator of the sensitivity of the outcome variable (SGRQ)

Table 5 Bivariate regressions

\begin{tabular}{|c|c|c|c|c|}
\hline Variable & Intercept & Slope & $\begin{array}{l}\text { Adjusted } \\
R^{2}\end{array}$ & $P$ \\
\hline \multicolumn{5}{|c|}{ Dependent variable: SGRQ } \\
\hline Education (yrs) & 70.63 & -1.43 & 0.13 & $<0.000$ I \\
\hline HUI3 & 74.65 & -33.86 & 0.37 & $<0.000$ I \\
\hline PSQI & 35.95 & 1.93 & 0.23 & $<0.000$ I \\
\hline FEVI\% & 70.63 & -0.29 & 0.04 & 0.0062 \\
\hline $\mathrm{CCl}$ & 51.07 & 0.90 & 0.02 & 0.0473 \\
\hline \multicolumn{5}{|c|}{ Nonsignificant predictors: BMI, age, ESS } \\
\hline \multicolumn{5}{|c|}{ Dependent variable: PSQI } \\
\hline BMI $\left(\mathrm{kg} / \mathrm{m}^{2}\right)$ & 7.05 & 0.15 & 0.017 & 0.0443 \\
\hline Education (yrs) & 12.53 & -0.17 & 0.022 & 0.0271 \\
\hline HUI3 & 14.57 & -6.92 & 0.239 & $<0.000$ I \\
\hline SGRQ & 3.99 & 0.12 & 0.23 & $<0.000$ I \\
\hline $\mathrm{CCl}$ & 8.8 & 0.33 & 0.04 & 0.0034 \\
\hline \multicolumn{5}{|c|}{ Nonsignificant predictors: age, ESS, FEV $\%$} \\
\hline \multicolumn{5}{|c|}{ Dependent variable: HUI3 } \\
\hline Education (yrs) & 0.325 & 0.020 & 0.08 & $<0.000$ I \\
\hline Age (yrs) & 1.008 & -0.007 & 0.05 & 0.0023 \\
\hline SGRQ & 1.147 & -0.010 & 0.37 & $<0.000$ I \\
\hline PSQI & 0.908 & -0.035 & 0.24 & $<0.000$ I \\
\hline $\mathrm{CCl}$ & 0.77 & -0.04 & 0.12 & $<0.000$ I \\
\hline \multicolumn{5}{|c|}{ Not significant predictors: ESS, $\mathrm{FEV} \%, \mathrm{BMI}$} \\
\hline
\end{tabular}

relative to changes in the others. For a 1 SD change in PSQI, there was a 0.49 SD change in the SGRQ.

Table 7 shows the associations between specific medication categories and HrQOL. For the SGRQ, use of oral steroids, antibiotics, inhaled parasympathetic blockers, and oral hypoglycemics was associated with improved HrQOL. For the PSQI, use of oral steroids and hypnotics was associated with improved sleep quality. Inhaled steroids

Table 6 Multivariate regression models

\begin{tabular}{|c|c|c|c|c|c|}
\hline \multirow[t]{2}{*}{ Variable } & \multirow[t]{2}{*}{ Slope } & \multicolumn{2}{|c|}{ Semipartial SE } & \multirow[t]{2}{*}{$\mathbf{T}$} & \multirow[t]{2}{*}{$P$} \\
\hline & & $R^{2}$ & estimate & & \\
\hline \multicolumn{6}{|c|}{ Dependent variable: SGRQ } \\
\hline Education & -0.73 & 0.03 & 0.23 & -3.19 & 0.0017 \\
\hline HUI3 & -23.00 & 0.12 & 3.72 & -6.18 & $<0.0001$ \\
\hline PSQI & 1.02 & 0.05 & 0.26 & 3.97 & 0.0001 \\
\hline $\mathrm{FEV}, \%$ & -0.21 & 0.02 & 0.08 & -2.706 & 0.0075 \\
\hline Constant & 74.77 & & & & \\
\hline Overall $R^{2}$ & 0.48 & & & & \\
\hline \multicolumn{6}{|c|}{ Dependent variable: PSQI } \\
\hline HUI3 & -4.43 & 0.06 & 1.14 & -3.88 & 0.0002 \\
\hline SGRQ score & 0.07 & 0.05 & 0.02 & 3.57 & 0.0005 \\
\hline Constant & 9.07 & & & & \\
\hline Overall $R^{2}$ & 0.30 & & & & \\
\hline \multicolumn{6}{|c|}{ Dependent variable: HUI3 } \\
\hline Age & -0.01 & 0.07 & 0.002 & -4.99 & $<0.000$ I \\
\hline SGRQ & -0.01 & 0.22 & 0.001 & -8.60 & $<0.0001$ \\
\hline PSQI & -0.015 & 0.03 & 0.005 & -3.25 & 0.0014 \\
\hline Constant & 1.84 & & & & \\
\hline Overall $R^{2}$ & 0.49 & & & & \\
\hline
\end{tabular}

Abbreviations: SGRQ, St Georges Respiratory Questionnaire; HUI3, Health Utilities Index 3; PSQI, Pittsburgh Sleep Quality Index; FEV \%, forced expired volume in I second as percent predicted. 
Table 7 Medication classes associated with differences in selected SGRQ, PSQI, and HUI3

\begin{tabular}{lllll}
\hline Medication & HrQOL index & Mean (SD) of those taking & Mean (SD) of those not taking & $P$ \\
\hline Oral steroids & SGRQ & $52.2(21.0)$ & $68.6(18.8)$ & 0.000 I \\
Antibiotics & SGRQ & $52.9(20.8)$ & $64.2(20.0)$ & 0.0005 \\
Inhaled parasympathetic & SGRQ & $53.5(21.0)$ & $60.0(21.0)$ & 0.0424 \\
blockers & & & \\
Oral hypoglycemics & SGRQ & $55.7(21.6)$ & $64.3(18.2)$ & 0.0409 \\
Oral steroids & PSQI & $10.4(5.3)$ & $12.3(5.3)$ & 0.03 \\
Inhaled steroids & PSQI & $12.1(5.4)$ & $10.3(5.2)$ & 0.0353 \\
hypnotics & PSQI & $10.5(5.4)$ & $13.7(3.4)$ & 0.0037 \\
Oral steroids & HUI3 & $0.58(0.36)$ & $0.38(0.39)$ & 0.0012 \\
Antibiotics & HUI3 & $0.58(0.36)$ & $0.41(0.40)$ & $0.006 \mathrm{I}$ \\
Hypnotics & $\mathrm{HUI3}$ & $0.54(0.37)$ & $0.37(0.44)$ & 0.0358 \\
\hline
\end{tabular}

Abbreviations: SGRQ, St Georges Respiratory Questionnaire; PSQI, Pittsburgh Sleep Quality Index; HUI3, Health Utilities Index 3; HrQOL, health-related quality of life.

were associated with worse sleep quality. For HUI3, oral steroids, antibiotics, and hypnotics were associated with improved HrQOL. Only $7.6 \%$ of the patients were taking antidepressants (data not shown), and use of these was not associated with differences in any measure of HrQOL. Finally, Table 2 shows the mean scores of HrQOL (HUI3 and SGRQ) and sleep quality (PSQI) among the different GOLD class severities of COPD. None of the differences was significant.

\section{Discussion}

In this study of patients, most of whom had moderate to severe COPD, we found: 1) general and disease-specific HrQOL was low; 2) most patients experienced poor sleep quality (PSQI); 3) low sleep quality predicted low diseasespecific and generic HrQOL. There was no relationship either between the degree of airflow obstruction ( $\left.\mathrm{FEV}_{1} \%\right)$ and general HrQOL (HUI3) and sleep quality (PSQI) or between GOLD class and HrQOL or sleep quality. To our knowledge, this is the largest study available examining the relationship between sleep quality and general and diseasespecific HrQOL. In the ensuing discussion, we consider these findings in light of currently available literature.

\section{HrQOL in COPD}

Normative data for the HrQOL indices reported here do not exist for the Israeli population. Even with the most rigorous translation and validation procedures, scores from a given population may in part reflect cultural norms, and caution is urged in comparing different populations.

We reported a mean SGRQ score of 57.0, but others ${ }^{5,11,12}$ have reported somewhat lower mean scores. Although we found that $\mathrm{FEV}_{1} \%$ was a significant correlate of SGRQ in both bivariate and multivariate models (Tables 5 and 6), we cannot attribute the lower scores reported by Nunes et $\mathrm{al}^{11}$ to lower $\mathrm{FEV}_{1} \%$, as this measure was similar to the one reported here. However, even with potential differences in cultural norms, the fact that within our group SGRQ scores were associated with $\mathrm{FEV}_{1}$ \% suggests that lung function is one determinant of COPD-specific HrQOL. On the other hand, neither the measure of HrQOL (HUI3, SGRQ) nor sleep quality (PSQI) was different among different GOLD severity classifications (Table 2). These data are consistent with the notion that self-assessed QOL is not necessarily predicted by the physiologic severity of airflow obstruction but is related to other factors, such as concomitant conditions, socioeconomic factors, education, and cultural factors.

The HUI3 has not been extensively evaluated in COPD. We found a mean score of 0.52 . This is lower than sleep disorders patients ${ }^{18}$ and considerably lower than normal population values of 0.86 to $0.9 .^{28,29}$ Our values are even lower than means from the datasets of Shaya et al and Sawka et al. ${ }^{30,31}$ By way of comparison, our patients have HUI3 scores comparable with patients recovering from stroke and with arthritis, and even lower than those reported in survivors of advanced neuroblastoma and Wilms' tumor. ${ }^{28,32}$ Thus, COPD imparts a heavy burden on general HrQOL.

As measured by the PSQI, 77.7\% of the patients reported disturbed sleep (PSQI $>5$ ), with long latencies to sleep (median 30 minutes) and short sleep times (median 5 hours). There was a large discrepancy between selfreported time in bed ( 8 hours) and the self-reported sleep times. This suggests a fair amount of wake after sleep onset and resultant sleep fragmentation. This is consistent with the finding that approximately three-quarters of the patients reported nocturnal awakenings. Future studies could be directed to objective assessment of sleep fragmentation in COPD. 
It should be noted that the PSQI is a score of self-rated quality of sleep and not a measure of sleep-related HrQOL, such as the Functional Outcomes of Sleep Quality score. ${ }^{33}$ The mean PSQI score reported here is greater (ie, rated worse) than that previously reported in COPD. ${ }^{11,12}$ It is not clear why this should be so. The extent of airflow obstruction as measured by $\mathrm{FEV}_{1} \%$ in the cited studies was similar to ours. However, comorbidity burden was not reported in the other studies. In our study, comorbidity burden (CCI) was a bivariate predictor of PSQI, although not significant on multivariate analysis. Possibly, the comorbidity burden in our patients was greater than in the other reports, influencing the estimation of sleep disturbances. Finally, the PSQI combines the symptoms of coughing and snoring in one question. It is possible that patients answering this question would actually overestimate the frequency of snoring by combining this symptom with coughing. In the Sleep Symptom Questionnaire, the symptom of nocturnal coughing was given by itself, and the prevalence was similar to that of "cough and snore" on the PSQI (Tables 3 and 4). This gives credence to the idea that the PSQI cannot be used to distinguish snore as a sign of sleep apnea from coughing when associated with COPD.

Interestingly, excessive sleepiness, as assessed by the ESS, was not a prominent part of the symptomotology in most patients, even though many reported disturbed sleep as judged by long sleep latency, short sleep time, and being unable to remain asleep. Thus, insomnia without excessive sleepiness was the primary sleep complaint reported by our patients. The reasons for the dissociation between short self-reported sleep times and lack of excessive sleepiness in many patients are not clear. However, the association between ESS scores and severity of disease in organic sleep disorders, such as OSA or objective measures of sleepiness, is not close, and the ESS may not reflect objective sleepiness. ${ }^{34}$ Cultural norms, difficulties with recall, and not wishing to acknowledge that one is sleepy can influence the ESS. It is also possible that medication use, sympathetic hyperstimulation, or anxiety could induce a "hyper alert" state, thereby diminishing the extent of excessive sleepiness and fragmenting sleep.

The presence of the classic symptoms as a sign of sleep apnea (snoring and/or witnessed apneas and daytime sleepiness) was rare in our patients, although approximately $15 \%$ were known to have OSA. The causes of insomnia in COPD are likely multifactorial. Anxiety and depression are common problems in patients with COPD, and HrQOL is correlated with depression/insomnia scores. ${ }^{12}$ Although few in our cohort were taking antidepressants, depression/anxiety may have been unrecognized by these patients or their physicians.
Other reasons for disturbed sleep could relate to the effects of nocturnal hypoxia/hypercarbia. ${ }^{6,7}$ Finally, as indicated below, medications used with COPD can affect sleep.

We showed no association between sleep quality (PSQI) or disease-specific (SGRQ) quality of life with age, as might be expected. Possibly, mean age was too high or age variability was too low. Alternatively, it may be that the effects of moderate to severe disease on QOL overwhelm any effects of age. In addition, although there was a bivariate association between CCI and QOL indices (Table 5), CCI did not remain as an independent predictor in the multivariate analyses (Table 6). It may be that components of the CCI themselves influence both sleep quality and QOL in variable ways.

\section{Medication use}

A number of medications used by COPD patients could potentially affect sleep quality. As seen in Table 7, most medication classes were associated with improved HrQOL and sleep quality. The exception was that inhaled steroids were associated with worse sleep quality (PSQI). It is not clear why this should be so. One interpretation is that use of the most common medications, including those for treatment of COPD, improves airflow or stabilizes airways at night, thus improving sleep quality. Possibly, the use of inhaled steroids, often given to minimize or eliminate the need for oral steroids, results in less effective stabilization of airway inflammation at night.

COPD medications are often thought by clinicians to fragment sleep. However, this has been difficult to document, as previous studies have not reported consistent worsening of sleep quality with some commonly used medication classes in COPD. Veale et $\mathrm{al}^{35}$ noted no change in sleep quality in 14 patients with COPD treated with a sustained-release form of salbutamol. The effects of theophylline on sleep quality have been more variable, with some studies demonstrating an impairment in sleep quality, ${ }^{36}$ whereas others have noted no significant effect. ${ }^{37}$ Anticholinergics, such as ipratropium, may improve sleep quality. ${ }^{38}$ More recently, McNicholas et $\mathrm{al}^{39}$ demonstrated that the long-acting anticholinergic tiotropium did not affect sleep quality after four weeks of treatment. Finally, there are few data available on the effects of oral steroids on sleep quality in COPD.

It is possible that COPD patients are "hyper alert" and do not have excessive daytime sleepiness in spite of reduced sleep time due to sympathetic hyperstimulation associated with airway obstruction, hypoxia, or medications. Regarding the latter, we found no association with methylxanthine use or inhaled beta-agonist use, agents 
that increase alertness. We did find that oral steroids and hypnotics were associated with changes in PSQI but in the direction of improved sleep quality, whereas inhaled steroids were associated with worse HrQOL. Use of oral steroids and antibiotics suggests the possibility of COPD exacerbation within the quarter (but not the month) prior to the survey, and this could have influenced HrQOL. Hypnotic use was associated with improved sleep quality, although worsening HUI3. The use of hypnotics could improve sleep quality but worsen general HrQOL if there are carryover effects the next day. We believe that the use of hypnotics in COPD patients with insomnia should be further explored.

\section{Associations between measures of sleep quality and $\mathrm{HrQOL}$}

The PSQI was a significant and independent predictor of disease-specific (SGRQ) and general HrQOL (HUI3). The $\mathrm{FEV}_{1} \%$ was correlated with SGRQ but not with HUI3. The correlation between SGRQ and $\mathrm{FEV}_{1} \%$ suggests that many symptoms recorded in the SGRQ are functions of the degree of airflow obstruction. These findings differ somewhat from previous studies in younger asthmatics ${ }^{23}$ in which the $\mathrm{FEV}_{1} \%$ was not a predictor of indices of asthma-related HrQOL. On the other hand, in asthmatics, as in our study, the PSQI was an independent predictor of HrQOL. ${ }^{23}$ Our studies confirm and extend previous smaller studies ${ }^{11,12}$ showing that sleep quality predicts overall and disease-specific HrQOL. Hence, it appears that sleep quality should be taken into account when considering HrQOL in COPD trials.

\section{Study limitations}

The survey methodology used here may be subject to recall bias. This is true of any surveys relying on patient recall. We attempted to minimize this by keeping the recall period to four weeks, but it must be acknowledged as a study limitation. We also attempted to minimize bias by using trained interviewers to administer the surveys. ${ }^{40}$ This study gathered data on medication use and comorbidity retrospectively from a database. We cannot ascertain whether patients actually took the medication they were issued, nor can we know if there were other comorbid conditions present that were not recorded. We also cannot objectively determine the prevalence of organic sleep disorders, such as OSA, as few underwent sleep testing. Additionally, nocturnal oxygen desaturation could contribute to nocturnal sleep disturbances. In our clinically stable patients, daytime oxygen saturations on room air were quite high. However, we have no data on nocturnal oxygenation in this group of patients. Future studies of quality of life and sleep disturbances should incorporate this important measure. We would point out that we excluded patients who had an exacerbation within the four weeks preceding the questionnaire. We acknowledge that symptoms from exacerbation can last for several months after this. Thus, it is possible that QOL in some patients reflects an exacerbation prior to the four-week period. Finally, we would point out that although sleep quality contributes to HrQOL in these patients, there are other, unmeasured, factors that likely contribute to QOL. In addition to what has been discussed previously, these include mental health issues (state of depression, anxiety), physiologic changes (hypoventilation at night), concomitant illnesses, family factors, and others. The fact that the sleep QOL measure (PSQI) contributed only 3\%-5\% of the variance (Table 6) to the different HrQOL indices indicates that other, unmeasured, factors likely play a role in determination of HrQOL in COPD patients.

\section{Conclusion}

Patients with COPD have poor HrQOL and a high prevalence of disturbed sleep. This was correlated with indices of disturbed sleep. Few patients reported daytime sleepiness in spite of severe sleep disturbances. Studies in COPD incorporating HrQOL as an outcome should take sleep quality into account.

\section{Acknowledgment}

The study was funded by a grant from the Dean's office, Faculty of Health Sciences, Ben-Gurion University of the Negev, Beersheba, Israel.

\section{Disclosure}

Drs Maimon, Simon-Tuval, Reuveni, and Tarasiuk have faculty appointments at Ben-Gurion University.

\section{References}

1. Hajiro T, Nishimura K, Tsukino M, Ikeda A, Oga T, Izumi T. A comparison of the level of dyspnea vs disease severity in indicating the health-related quality of life of patients with COPD. Chest. 1999; 116:1632-1637.

2. Schlecht NF, Schwartzman K, Bourbeau J. Dyspnea as clinical indicator in patients with chronic obstructive pulmonary disease. Chron Resp Dis. 2005;2:183-191.

3. Mahler DA, Faryniarz K, Tomlinson D, et al. Impact of dyspnea and physiologic function on general health status in patients with chronic obstructive pulmonary disease. Chest. 1992;102:395-401.

4. Jones PW. Health status measurement in chronic obstructive pulmonary disease. Thorax. 2001;6:880-887.

5. Benzo R, Farrell MH, Chang $\mathrm{CCH}$, et al. Integrating health status and survival data. The palliative effect of lung volume reduction surgery. Am J Resp Crit Care Med. 2009;180:239-246.

6. Krachman S, Minai MA, Scharf SM. Sleep abnormalities and treatment in emphysema. Proc Am Thorac Soc. 2008;5:536-542. 
7. Collop N. Sleep and sleep disorders in chronic obstructive pulmonary disease. Respiration. 2009 Nov 12. [Epub ahead of print].

8. Wynne JW, Block AJ, Hemenway J, Hunt LA, Flick MR. Disordered breathing and oxygen desaturation during sleep in patients with chronic obstructive lung disease. Am J Med. 1979;66:573-579.

9. Calverley PM, Brezinova V, Douglas NJ, Catterall JR, Flenley DC. The effect of oxygenation on sleep quality in chronic bronchitis and emphysema. Am Rev Respir Dis. 1982;126:206-210.

10. Cormick W, Olson LG, Hensley MJ, Saunders NA. Nocturnal hypoxaemia and quality of sleep in patients with chronic obstructive lung disease. Thorax. 1986;41:846-854.

11. Nunes DM, Mota RMS, de Pontes Neto OL, Pereira ED, de Bruin VM, de Bruin PF. Impaired sleep reduces quality of life in chronic obstructive pulmonary disease. Lung. 2009;187:159-163.

12. Hynninen MJ, Pallesen S, Nordhus IH. Factors affecting health status in COPD patients with comorbid anxiety or depression. Int J Chron Obstruct Pulmon Dis. 2007;2:323-328.

13. American Thoracic Society. Standardization of spirometry 1994 update. Am J Resp Crit Care Med. 1995;152:1107-1136.

14. Global Initiative for Chronic Obstructive Lung Disease. MCR Vision, Inc. 2006.

15. Chien WT, Norman I. The validity and reliability of a Chinese version of the family burden interview schedule. Nursing Res. 2004;53: 314-322.

16. Feeny D, Furlong W, Saigal S, Sun J. Comparing directly measured standard gamble scores to HUI2 and HUI3 utility scores: group- and individual-level comparisons. Soc Sci Med. 2004;58:799-809.

17. Furlong WJ, Feeny DH, Torrance GW, Barr RD. The Health Utilities Index (HUI) for assessing health related quality of life in clinical studies. Ann Med. 2001;33:375-384.

18. Welch K, Scharf SM. Construct validity for the Health Utilities Index in a sleep center. Sleep Breath. 2007;11:295-303.

19. Jones PW, Quirk FH, Baveystock CM, Littlejohns P. A selfcomplete measure of health status for chronic airflow limitation: the St George's Respiratory Questionnaire. Am Rev Respir Dis. 1992;145: 1321-1327.

20. Meguro M, Barley EA, Spencer S, Jones PW. Development and validation of an improved, COPD-specific version of the Saint George's Respiratory Questionnaire. Chest. 2007;132:456-463.

21. Buysse DJ, Reynolds CF 3rd, Monk TH, Berman SR, Kupfer DJ. The Pittsburgh sleep quality index: a new instrument for psychiatric practice and research. Psychiatry Res. 1989;28:192-213.

22. Johns MW. A new method for measuring daytime sleepiness: the Epworth sleepiness scale. Sleep. 1991;14:540-545.

23. Mastronarde JG, Wise RA, Shade DM, Olopade CO, Scharf SM. Sleep quality in asthma: results of a large prospective clinical trial. J Asthma. 2008;45:183-189.

24. Lin PJ, Shaya FT, Scharf SM. Economic implications of comorbid conditions among Medicaid beneficiaries with COPD. Respir Med. 2009 Dec 1. [Epub ahead of print].

25. Vilkman S, Keistinen T, Tuuponen T, Kivelä SL. Survival and cause of death among elderly chronic obstructive pulmonary disease patients after first admission to hospital. Respiration. 1997;64:281-284.

26. Deyo RA, Cherkin DC, Ciol MA. Adapting a clinical comorbidity index for use with ICD-9-CM administrative databases. J Clin Epidemiol. 1992;45:613-619.
27. O'Connell RL, Lim LL-Y. Utility of the Charlson comorbidiy index computed from routinely collected hospital discharge diagnosis codes. Methods Inf Med. 2000;39:7-11.

28. Grootendorst P, Feeny D, Furlong W. Health Utilities Index mark 3: evidence of construct validity for stroke and arthritis in a population health survey. Med Care. 2000;38:290-299.

29. Luo N, Johnson JA, Shaw JW, Feeny D, Coons SJ. Self-reported health status of the general adult US population as assessed by the EQ-5D and Health Utilities Index. Med Care. 2005;43:1078-1086.

30. Shaya FT, Samant ND, Pradel FG, Mullins CD, Scharf SM, Britt EJ. Health-related quality of life as a potential predictor in chronic obstructive lung disease patients. Expert Rev Pharmacoecon Outcomes Res. 2007;7:129-135.

31. Sawka AM, Thabane L, Papaioannou A, Gafni A, Ioannidis G, Papadimitropoulos EA. Health-related quality of life measurements in elderly Canadians with osteoporosis compared to other chronic medical conditions: a population-based study from the Canadian Multicentre Osteoporosis Study (CaMos). Osteoporos Int. 2005;16: 1836-1840.

32. Szecket N, Medin G, FurlongWJ, Feeny DH, Barr RD, Depauw S. Preliminary translation and cultural adaptation of Health Utilities Index questionnaires for application in Argentina. Int J Cancer Suppl. 1999; $12: 119-124$

33. Weaver TE, Laizner AM, Evans LK, Maislin G, Chugh DK, Lyon K. An instrument to measure functional status outcomes for disorders of excessive sleepiness. Sleep. 1997;20:835-843.

34. Fong SY, Ho CK, Wing YK. Comparing MSLT and ESS in the measurement of excessive daytime sleepiness in obstructive sleep apnoea syndrome. J Psychosomatic Res. 2005;58:55-60.

35. Veale D, Cooper BG, Griffiths CJ, Corris PA, Gibson GJ. The effect of controlled-release salbutamol on sleep and nocturnal oxygenation in patients with asthma and chronic obstructive pulmonary disease. Respir Med. 1994;88:121-124.

36. Mulloy E, McNicholas WT. Theophylline improves gas exchange during rest, exercise and sleep in severe chronic obstructive pulmonary disease. Am Rev Respir Dis. 1993;148:1030-1036.

37. Martin RJ, Pak J. Overnight theophylline concentrations and effects on sleep and lung function in chronic obstructive pulmonary disease. Am Rev Respir Dis. 1992;145:540-544.

38. Martin RJ, Bucher Bartelson B, Smith P, Hudgel DW, Lewis D, Pohl G. Effect of ipratropium bromide treatment on oxygen saturation and sleep quality in COPD. Chest. 1999;115:1338-1345.

39. McNicholas WT, Calverley PM, Lee A, Edwards JC. Long-acting inhaled anticholinergic therapy improves sleeping oxygen saturation in COPD. Eur Respir J. 2004;23:825-831.

40. Nunnally J, Bernstein I. Special problems in classical test theory. Psychometric Theory. New York: McGraw-Hill; 1994:376-386.

41. Cronbach LJ. Coefficient alpha and the internal structure of tests. Psychometrika. 1951;16:297-333.

42. Nunnally JC. Psychometric Theory. New York, NY: McGraw-Hill; 1978.

43. Von Neumann J, Morgenstern O. Theory of games and economic behaviour. Princeton, NJ: Princeton University Press; 1944.

44. Le GC, Buron C, Costet N, et al. Development of a preference-weighted health status classification system in France: the Health Utilities Index 3. Health Care Manage Sci. 2002;5:41-51. 


\section{Methods supplement}

\section{Questionnaire validation}

\section{and reliability testing}

The questionnaires included the Health Utilities Index (HUI), Pittsburgh Sleep Quality Index (PSQI), St George's Respiratory Questionnaire (SGRQ), and a convenience questionnaire we have called the Sleep Symptom Questionnaire. We used a previously validated Hebrew version of the Epworth Sleepiness Scale (ESS) that is currently in use at the sleep laboratory of the Soroka University Medical Center. For this study, the HUI, PSQI, SGRQ, and Sleep Symptom Questionnaire were independently translated into Hebrew by two bilingual native Hebrew speakers with medical expertise. The Hebrew versions were then reviewed by one of the translators, a practicing Israeli pulmonologist, and merged into a single document that was reviewed again. Translators were instructed to base the translations on the intent of the question, not the literal meaning, to make the questions culturally meaningful and to attempt to translate at approximately the sixth grade level. The translated documents were then independently translated back into English by two bilingual native English speakers with medical expertise who had not been involved in the original translation. The back-translated version was reviewed by a member of our team (SMS) who was not on either translation committee. Discrepancies between the original English and the backtranslated versions were brought to the attention of the translation committees for reconciliation.

Test-retest reliability was also examined by readministering the questionnaires to 15 participants within two months of their original questionnaire submission, and the results between the two sets were compared using paired $t$-tests. There were no statistically significant differences between the HUI, PSQI, SGRQ, and the previous Hebrew version of the ESS administered at the two time points.

The reliability and internal consistency of the Hebrew version of the scales were examined using Cronbach's alpha. ${ }^{41}$ The Cronbach's alpha for the HUI3 was 0.818 and compared well to a random selection of chronic obstructive pulmonary disease (COPD) patients from a previous American study ${ }^{30}$ with Cronbach's alpha $=0.837$. The Cronbach's alpha for the PSQI was 0.746 . We did not have a previous data set with which to compare this. The Cronbach's alpha for the SGRQ was 0.916 and compared favorably with a random, anonymized selection of COPD patients from a previous American study (courtesy John Connett, University of Minnesota; Cronbach's alpha $=0.815$ ). For the questions on the Sleep Symptom Questionnaire, the alpha was 0.911. An alpha of $\geq 0.7$ is generally considered acceptable for group comparisons. ${ }^{42}$

\section{Patients and setting}

The study was performed at the Pulmonary Clinic of the Soroka University Medical Center in Beer Sheba, Israel. This is a large (1000 bed) tertiary care academic medical center and is the major clinical affiliate of the Faculty of Health Sciences, Ben-Gurion University. The Soroka University Medical Center Ethics Committees approved the protocol.

This questionnaire survey was performed from February 2009 to December 2010 on a convenience sample of patients coming to the pulmonary clinic for routine follow-up with a diagnosis of COPD made by one of the pulmonary specialists. A total of 200 patients were approached to participate and 180 agreed. Inclusion criteria were: 1) age $>35$ years; 2) smoking history of at least 10 pack-years; 3) COPD previously diagnosed by a pulmonary specialist based on history of smoking, airflow obstruction on spirometry, and the presence of at least one symptom of COPD (ie, exercise-limiting dyspnea, chronic cough, sputum production); 4) stability of disease defined as no exacerbations within at least one month; 5) no history of hospitalization or urgent care visit within one month for any other reason; and 6) sufficient knowledge of Hebrew to give informed consent, to understand the questions, and to give answers. Exclusion criteria were: 1) another major pulmonary diagnosis, including asthma, bronchiectasis, and pulmonary fibrosis; or 2) the presence of disease expected to shorten life span to less than three years. All questionnaires were for one month recall and were administered face to face by trained interviewers.

\section{Lung function}

Spirometric indices of lung function were obtained on the day of questionnaire administration according to standards set by the American Thoracic Society. ${ }^{13}$ These included forced vital capacity (FVC), forced expired volume in one second $\left(\mathrm{FEV}_{1}\right)$, and the ratio $\mathrm{FEV}_{1} / \mathrm{FVC}$. COPD severity was staged according to the Global Initiative for Lung Disease (GOLD) 2006 guidelines. ${ }^{14}$

\section{Demographic information}

Patient age, gender, body mass index (BMI), current smoking status (current, ex-smoker [defined as no smoking for at least one month]), and pack-years smoking were ascertained on the day of the interview. 


\section{Socioeconomic status}

The subjects were asked four questions regarding their socioeconomic status: 1) income relative to the Israeli average of 8000 NIS per month (much lower, lower, equal to, higher, much higher); 2) years of schooling; 3) employment status (employed, unemployed, on pension); and 4) marital status (married, divorced, widowed, separated, bachelor/ette).

\section{Questionnaires \\ Generic HrQOL instrument}

Health Utilities Index (HUI)

The HUI system ${ }^{16,17}$ represents a generic quality of life (QOL) measurement that includes two active systems, known as the HUI2 and HUI3. Both separately, but in a complementary manner, classify health status and establish a preference-based scoring system. The attributes of the HUI2 include sensation, mobility, emotion, cognition, self-care, pain, and fertility. Each of these attributes has three to five levels (ie, descriptions of health status worded directly in the questionnaire). Similarly, the HUI3 consists of eight attributes with five to six levels each. The attributes of the HUI3 include vision, hearing, speech, ambulation, dexterity, emotion, and cognition. Although several attributes within the HUI2 and HUI3 appear to be similar and to encompass overlapping disease states, all attributes were designed to be structurally independent. Together, the HUI2 and HUI3 measures account for approximately one million individual health states. This is possible because each attribute within the HUI2 or HUI3 exists independently of the others, and levels within each attribute do not affect the levels within other attributes. The 17-point HUI2/3 questionnaire is scored with a formula in accordance with von Neumann-Morganstern utility theory. ${ }^{43}$ The questionnaire has been validated in 14 languages, ${ }^{32,44}$ has recall periods of one, two, and four weeks, and a usual long-term health follow-up. Therefore, the survey can be used in a wide variety of patients to assess HrQOL over several time periods. The utility score (a score measuring patient preference for one disease state over another) for a population of patients is expressed from 0.0 to 1.00 (perfect health). Where the HUI is concerned, disease states, rated as worse than death (eg, -0.3 ) are possible. The HUI2, in part, derives from answers on the HUI3 and was highly correlated with it $(R=0.88)$. All correlations seen with the HUI3 were also seen with the HUI2. In the present study, little additional information was gained by inclusion of the HUI2. Hence, for simplicity, we present only the HUI3 scores in this study. The HUI system was recently validated against a population of patients with sleep disorders. ${ }^{18}$

\section{Disease-specific HrQOL instrument COPD-specific: St George's Respiratory Questionnaire}

The SGRQ is designed to measure the impact of respiratory disease on HrQOL and well-being. ${ }^{19}$ Responses to its 53 items are expressed as an overall score in the domains symptoms, activity, and impact. The scores range from $0 \%$ (best) to $100 \%$ (worst). Previous results provide strong evidence that the SGRQ is valid and responsive. ${ }^{19,20}$

\section{Instruments rating sleep quality}

Pittsburgh Sleep Quality Index (PSQI)

This is a 19-item self-rating scale designed to measure perceived quality of sleep. The components are weighted and a global score of $0-21$ is derived, with increasing score meaning worse sleep quality. A global score of $>5$ is accepted as differentiating good from poor sleepers. ${ }^{21}$

\section{Epworth Sleepiness Scale}

In this metric, the subject is asked to rate the probability of falling asleep on a scale of increasing probability from 0 to 3 in eight different situations. ${ }^{22}$ The scores for the eight questions are added to obtain a single number. A number in the range $0-9$ is considered normal, whereas a number in the range 10-24 indicates excessive sleepiness and the need for referral to a sleep specialist.

\section{Sleep Symptom Questionnaire ${ }^{23}$}

The Sleep Symptom Questionnaire (Figure 1) was originally used to elicit specific nocturnal symptoms in a study of HrQOL in patients with asthma and consists of eight questions about the frequency of specific respiratory and nonrespiratory symptoms at night. The respiratory symptoms include wheezing, cough, dyspnea, and chest pains. The nonrespiratory symptoms include heartburn, worry/anxiety, intrusive thoughts, and palpitations. There is no weighting of answers and no composite score is generated. Answers to each question are given as the frequency of these symptoms in nights per week.

\section{Comorbidity burden}

The comorbidity burden has been shown to be a determinant of health care utilization in COPD. ${ }^{24}$ Accordingly, data on selected comorbidities were collected from the central database of the major health maintenance organization in Israel, the Clalit Health Services. Comorbidity burden was measured using the age-adjusted Charlson Comorbidity Index 
(CCI) with the Deyo modification. ${ }^{25,26}$ The CCI originally was developed as a risk measure of one-year mortality rate based on hospital chart abstraction, but it has been adapted for use with International Classification of Disease (ICD)-9 diagnostic codes. ${ }^{27}$ The CCI contains 17 categories of comorbidities with each assigned a weight of 1, 2, 3, or 6, reflecting the magnitude of the adjusted relative risks associated with each comorbidity. The CCI score then sums the weights for all conditions with a total maximum score of 33 . We also recorded whether patients had previously undergone formal sleep testing or had a diagnosis of concomitant obstructive sleep apnea (OSA), whether they had undergone evaluation for treatment with continuous positive airway pressure (CPAP), and whether this treatment had been ordered.

\section{Medication use}

We obtained data on specific medication categories issued to the patients in the quarter prior to the administration of the questionnaires from the database of the Clalit Health Services. The categories of medication were listed according to the World Health Organization (WHO) drug listing. The categories and WHO classification numbers were as follows: inhaled beta-agonists (R03 AC), inhaled steroids (R03BA), inhaled antiparasympathetics (R03BB), antileukotrienes (R03DC), methylxanthines R03DA), antibiotics (J01), systemic steroids (H02 AB), chemotherapy (L01), ACE inhibitors (C09 A), diuretics (C03), antidepressants (N06 A), antipsychotics (N05 A), beta-blockers (C07), statins (C10 AA), insulin (A10 A), oral hypoglycemics (A10B), hypnotics (N05C), digoxin (C01 AA05), opiates (R05D), and calcium channel blockers (C08). Individuals taking combination inhalers (eg, inhaled steroid, inhaled beta agonist combination) were coded as taking each of the components.

Data on comorbidity burden and medication use could not be gathered on three of the patients because they were not members of Clalit Health Services. Thus, data on comorbidity burden and medication use represent 177 patients. All other data, however, could be collected on the entire cohort $(n=180)$.

\section{Data analysis}

Data were compiled and expressed as mean \pm standard deviation (SD), as well as median and 25 th and 75 th percentiles. To establish associations between variables, Pearson product-moment coefficients were calculated. Regression analysis was carried out using the least-squares technique. Significant bivariate associations were then entered into a backwards stepwise multivariate regression model to determine significant predictors of assigned independent variables. Differences between means were tested using Student's $t$-test for unpaired variates. In the rare case when data were not normally distributed (Kolmogorov-Smirnoff test), the Mann-Whitney $U$ test was used to determine statistical significance. Rates and proportions were tested using the Chi-square test. The null hypothesis was rejected at the $5 \%$ level. Differences in indices of HrQOL with different levels of COPD severity (GOLD) were tested using one-factor analysis of variance (ANOVA), data analysis was performed using Statistical Package for the Social Sciences, version 17 (SPSS Inc, Chicago, IL, USA) or GBstat v9 (Dynamic Microsystems Inc, Silver Spring, MD, USA).
International Journal of COPD

\section{Publish your work in this journal}

The International Journal of COPD is an international, peer-reviewed journal of therapeutics and pharmacology focusing on concise rapid reporting of clinical studies and reviews in COPD. Special focus is given to the pathophysiological processes underlying the disease, intervention programs, patient focused education, and self management protocols.

\section{Dovepress}

This journal is indexed on PubMed Central, MedLine and CAS. The manuscript management system is completely online and includes a very quick and fair peer-review system, which is all easy to use. Visit $\mathrm{http}: / /$ www.dovepress.com/testimonials.php to read real quotes from published authors. 